\title{
USING MATURITY MODEL AND DISCRETE-EVENT SIMULATION FOR INDUSTRY 4.0 IMPLEMENTATION
}

\author{
Gajsek, B. ${ }^{*}$; Marolt, J. ; Rupnik, B. ; Lerher, T. ${ }^{* *} \&$ Sternad, M. \\ *University of Maribor, Faculty of Logistics, Mariborska 7, 3000 Celje, Slovenia \\ ${ }^{* *}$ University of Maribor, Faculty of Mechanical Engineering, Smetanova 17, 2000 Maribor, Slovenia \\ E-Mail: brigita.gajsek@um.si, jakob.marolt@um.si,bojan.rupnik@um.si, tone.lerher@um.si, \\ marjan.sternad@um.si
}

\begin{abstract}
Production environments worldwide transform themselves in order to take the best advantage of the Industry 4.0 guidelines. Automation, data exchange, cyber-physical systems, the IoT, cloud and cognitive computing represent a step in the unknown to these companies, associated with high risks and also the need to restructure their culture. If the execution route is not clearly defined and understandable to all levels of employees, the renovation is too long. The maturity models can be used for the assessment of current Industry 4.0 maturity level, but the practical use of scores and assessed level often requires the involvement of consulting firms. Companies can avoid the involvement of consulting companies with the use of complementary tools. In this paper, we propose a new methodology that combines the Industry 4.0 maturity model and discrete-event simulation tools in the case of steel production company with the possibility of generalization. The combination of these tools in the first step helps the company to assess its current level of maturity for Industry 4.0, and in the second step helps to consider about strengths and weaknesses of possible scenarios for transition to a higher level of maturity.

(Received in June 2019, accepted in August 2019. This paper was with the authors 2 weeks for 1 revision.)
\end{abstract}

Key Words: Industry 4.0, Maturity Model, Steel Production, Discrete Event Simulation, Performance Analysis

\section{INTRODUCTION}

In line with rapidly changing customer demands, ever-intensified market competition, growing product complexity and demanding legal requirements, there is a high demand on improved production efficiency, product quality, energy consumption and cost containment for manufacturing companies [1]. Companies see Industry 4.0 as one of the solutions for their survival in a modern business environment due to improved productivity and economic gains [2]. Since the emergence of the idea until today, more and more companies and nations are joining the movement with different approaches to stay competitive. Industry 4.0 encloses several technological concepts, such as interoperability among different systems, semantics between machines, decentralization, cyber-physical systems (CPS), virtualization, automation and others [3]. A good information system is required to connect different concepts. Automation of the collection and processing of information is important for process improvement [4]. Several fields of knowledge can contribute to this end, such as robotics, materials, information, informatics, manufacturing among other fields, including DiscreteEvent Simulation (DES), which can play a very relevant role [3, 5, 6].

It is obvious that Industry 4.0 covers a very wide application area in the manufacturing industry and provides a wide range of options for combining different approaches and technologies. This diversity is, in all likelihood, also an obstacle to the relatively slow implementation of the idea in practice. On one hand, there is a large awareness of the importance of digitization and Industry 4.0 but on the other hand, the activities of the enterprises to prepare for it are not very extensive yet [7]. Veza et al. [8] found out that not using different production principles could present one of the main obstacles to Industry 4.0 
development. Production companies are indeed willing to face digitization/Industry 4.0, but risks/obstacles reduce their readiness or slow down the process [7]. Many have a vision of Industry 4.0 output, but no idea about its implementation since only pilots are built in practice [9]. Due to the complexity and uniqueness of individual modern system, copying or transferring solution from one plant to another is hardly applicable. In order to facilitate the transition, consulting firms have developed Industry 4.0 maturity models, which companies rarely know and are even more rarely used. Different maturity models are developed to describe evolution stages and maturation paths to the desired end states, in case of Industry 4.0 that would be smart factory. From the definition of the maturity model, we can conclude that it could be an appropriate guiding tool on the path to Industry 4.0. Its use gives information about current Industry 4.0 maturity but rarely precise guidelines on how to achieve a higher level of maturity. At this point, the use of a tool for testing different combinations of technological solutions, decision algorithms, organizational arrangements, layouts and other potential elements of the production system is required.

The problem that companies are dealing with is how to tackle the transition to Industry 4.0. The paper contributes directly to this gap and offers a new proposal of combining Industry 4.0 maturity model and discrete-event simulation tested on the case of a steel production company. However, the proposed methodology can be applied to any other production environment.

This paper consists of six sections. The first section presents the starting point and problem of the paper. This is followed by a theoretical background with an overview of the research findings of Industry 4.0 and simulation in production systems. The third section presents the methodology and general assumptions. The fourth section presents the results of Industry 4.0 maturity assessment and simulation. This section is followed by discussion of maturity assessment and simulation results. The paper concludes with a presentation of key findings.

\section{THEORETICAL BACKGROUND}

\subsection{Industry 4.0}

Industry 4.0 (Industry 4.0, I40) is a national strategic initiative, launched in 2011 from the German government through the Ministry of Education and Research (BMBF) and the Ministry for Economic Affairs and Energy (BMWI) [10]. It aims to drive digital manufacturing forward by increasing digitisation and the interconnection of products, value chains, and business models. It also aims to support research, the networking of industry partners and standardisation. According to [11], Industry 4.0 aims for optimisation of value chains by implementing autonomously controlled and dynamic production. Enablers are the availability of real-time information and networked systems [12] that require a higher degree of automation. Instruments to reach this increased automation are CPS equipped with microcontroller, actuators, sensors and a communication interface. CPS can work autonomously and interact with the production environment; in parallel, a factory becomes "smart" [12]. The department of Innovative Factory Systems (IFS) at the German Research Center for Artificial Intelligence (DFKI) identified four enablers for the Smart Factory, named Smart Products, Smart Machines, Smart Planner, and Smart Operators [12]. Smart Products know their production process and negotiate it with Smart Machines. The Smart Planner optimises processes in nearly real time. In this environment, humans take a central position. Supported by innovative ICT, they become Smart Operators who supervise and control ongoing activities. Industry 4.0 describes the increasing digitisation and automation of the manufacturing environment, as well as the creation of digital value chains to enable communication between products, their environment, and business partners [13]. Industry 4.0 
requires the introduction of modern manufacturing technologies, but Prester et al. [14] have found that investments into advanced manufacturing technologies do not have a positive effect on profits, but maybe brings benefits in time.

\subsection{Industry 4.0 maturity model}

Industry 4.0 maturity model is based on the assumption of predictable patterns of evolution and change. According to [15], it includes a sequence of levels that together form a logical path from an initial state to maturity and can be used in three application-specific purposes; these are descriptive, prescriptive and comparative. A maturity model serves a descriptive purpose of use if it is applied for assessments of system's current state where the current capabilities of the entity under investigation are assessed with respect to given criteria [16]. It serves a prescriptive purpose of use if it indicates how to identify desirable maturity levels and provides guidelines on improvement measures [16]. Comparative purpose of use is achieved if it allows for internal or external benchmarking [15].

\subsection{Simulation and production systems}

Rodič [17] emphasizes the influence of Industry 4.0 on the development of the new simulation methods, which are important for increasing competitiveness. Different simulation methods and simulation software [18] were used in manufacturing systems. Gingu et al. [19] used decomposition methods for flow modelling in production systems. They found out, that proposed method helps production companies to synchronize the production with the market demand. Constant market changes require the economic efficiency of companies. Simulation helps to improve material flow in production companies in terms of economic efficiency and time savings [20]. Production time is important to be competitive, so companies need to look for time savings in production. Grguraš and Kramar [21] applied fused deposition modelling to achieve shorter production time when they using bigger nozzle size instead of standard nozzle size.

For improvement of material flow, Kampa et al. [22] used discrete event simulation to improve manufacturing system. They found positive economic effects of using discrete event simulation on the production system. Discrete event simulation can be also supported by genetic algorithm optimization tool for determining the order and size of the product batches [23] and for improvement of performance indicators [24].

\subsection{Conclusion from the literature review}

The Scientific Community is attempting to define Industry 4.0 and maturity model. The simulations in regard to Industry 4.0 are always used for an exact, specific problem in an industrial environment. The problem is that companies do not know how to tackle the transition to Industry 4.0. In this paper, we developed a methodology that suggests logical steps from assessed current state to the next level on the Industry 4.0 maturity scale.

The contribution of this paper is to show to the research community how the simulation supports the company towards the implementation of the Industry 4.0 solutions (maturity index). In other words, how simulation supports managers in understanding the level of automation and robotization, which can be applied in their production process.

\section{METHODOLOGY AND GENERAL ASSUMPTIONS}

A case study was carried out in a steel plant company, which produces a vast variety of different steel bars by changing the shape and dimensions of a steel profile, increasing or decreasing the length of steel bars, and by altering the chemical compound of the steel. 
The study was organized in two steps. In the first step, company's current Industry 4.0 and digitalisation maturity were defined by using two maturity models, one for Industry 4.0 maturity assessment and one for digitalisation maturity assessment. Evaluation process pointed on company's weakest area with lowest ratings of maturity. The process defined starting point from which company had an insight into the next level of maturity or the target state that they can achieve by renewal. The transition from a lower to a higher degree of maturity can be carried out with different technologies, organizational approaches, decision algorithms, etc. This reflection was already part of the second step of our study.

In the second step, it was necessary to determine less developed area with what improvements the degree of automation and digitization can be increased. Logistics operations between production and warehouse were recognized as one opportunity for advancing the automation level and secondly also the IT support. At current state production and warehouse act as information islands. The current internal transport of finished goods from production to the warehouse is manual and unpredictable. Full or partial automation of this process is analysed by redefining the process by using automated transport. The feasibility of introducing and changing the process is tested with simulation.

\subsection{Challenge identification for shifting to a higher degree of Industry 4.0 maturity}

Literature review was used to learn about the methodology of assessment by using two different maturity models, namely the Industry 4.0 Maturity Index [25] and the Digital Maturity Model 4.0 [26]. Results are presented in [9, 27], and the characteristics of the workplace according to the guidelines of the Industry 4.0. The theoretical background about maturity models was set from scientific papers found in Google scholars, Web of Science and Elsevier.

The Industry 4.0 Maturity Index approach is based on the succession of maturity stages, i.e. value-based development levels that help companies navigate their way through every stage in the transformation, from the basic requirements for Industry 4.0 to full implementation. This model was used to assess company's 4.0 maturity level.

The second maturity model, the Digital Maturity Model 4.0, was prepared as a reserve scenario. It would be used, if the Industry 4.0 Maturity Index would classify observed company in stage one (computerisation) or stage 2 (connectivity). That would mean that company should start with improvements in digitalisation and automation. With use of second maturity model for digitalisation, we would assess digitalisation maturity, which would give us a better insight into the necessary improvements. If the Industry 4.0 Maturity Index would classify observed company in stage three (visibility) or stage four (transparency) or stage 5 (predictive capacity) or stage 6 (adaptability) no further evaluation would be necessary.

The Digital Maturity Model 4.0 is a self-assessment tool in a form of a questionnaire, which consists of 28 statements, 7 in each dimension. Respondents marked on a 4-point scale how much do they agree with each of the statements $(0$ - completely disagree, 1 - somewhat disagree, 2 - somewhat agree, 3 - completely agree). The sum of points places assessed company in one of four classes: a sceptic, adopter, collaborator, or differentiator.

In parallel, with the help of Business Process Modelling, we recorded the AS-IS process state and critically evaluated it. With the help of employees, we defined the main phases of the business process, which add value to the client. A guided tour was organized along workplaces on the value chain from the customer order to the dispatch from the factory. Data about the process and its resources was gathered with partially structured interviews with employees. In the critical evaluation of the AS-IS state, we analysed each individual activity within the process. We were interested in whether the activity is routine/repetitive, ergonomically unacceptable, unnecessary, without added value, it represents a loss in terms of lean paradigm, technologically upgradable from manual to machine, using paper documents. 
Based on the results from maturity assessment and critical analysis of AS-IS state, we proposed area with higher potential for improvements as input for the second research step.

\subsection{Solving the challenge by using DES}

A case study was carried out in a steel plant company. The main competitive advantage of the company is its flexibility. They can fulfil an order in approximate one-month time. To realize this high flexibility, the logistics operations need to ensure fast material flow through production. Their production predominantly produces circular (rolled round) and rectangular (flat) profile shape of steel bars. Furthermore, they can alternate the alloy elements, dimensions and length of the bars and profiles to achieve a vast assortment of different end products. At the end of the production, the steel bars are strapped together into a set of steel bars (SSB), which represent a basic storage keeping unit. The area restriction demands that the production line for each profile shape type is separated. The rectangular shape profile production line continues towards the product warehouse (Fig. $1-$ B), though the circular shape profile is orientated in the opposite direction away from the product warehouse (Fig. 1 - A). The transportation of the SSBs from the end of the production to the product warehouse is a crucial logistic step. While the rectangular profile shape SSBs are exclusively transported with an overhead crane over a short distance, the transportation of circular shape SSBs characterizes a bottleneck in the production. The transportation of circular SSBs is currently accomplished with a combination of overhead (industrial) cranes and tractors with small load capacity.

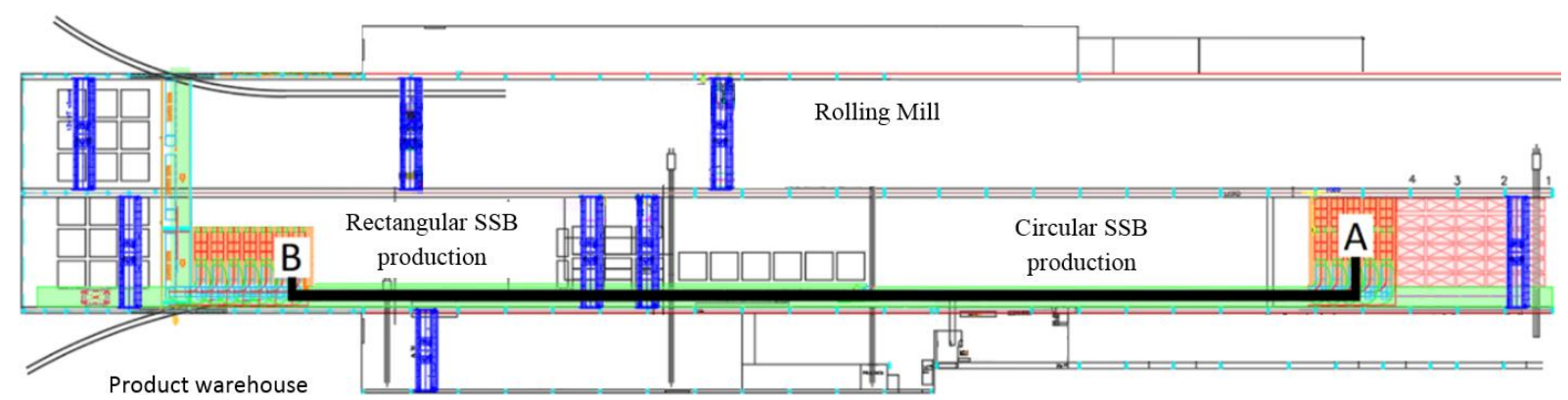

Figure 1: Layout of the steel plant company.

The company therefore plans to invest into automated heavy load vehicle for the transportation of the circular shape SSBs. In the future state, the circular SSB ought to be placed into special steel cassettes with an overhead crane at the end of the production. Full cassettes are then transported one by one to the cassette buffer near the product warehouse. From the cassette buffer, the circular shape SSBs must be further moved from the cassettes to the product warehouse with an overhead crane. The overhead crane role in the future state will be to systematically empty both the circular SSBs and the rectangular SSBs from the buffers, based upon real time material flow information. The discrete event simulation will evaluate the maximum performance of the production with an automated heavy load vehicle performing the main transportation of the circular SSBs.

Discrete-event simulation has been used to predict the behaviour of the proposed solution. The model considers the following components:

- $Q_{C}$ - buffer for steel cassettes at the end for the circular SSB production,

- $Q_{W}$ - buffer for steel cassettes at the product warehouse,

- $Q_{R}$ - buffer for rectangular SSBs at the product warehouse,

- $C$ - steel cassette for circular SSBs,

- Heavy load vehicle - transportation of steel cassettes for circular SSBs between $Q_{C}$ and $Q_{W}$, 
- Overhead crane - used for unloading SSBs from the steel cassettes at $Q_{B}$ as well as rectangular SSBs in $Q_{R}$ to the product warehouse.

Due to spatial restrictions, the buffer capacities for steel cassettes are limited to $C_{C}=10$ pieces at $Q_{C}$ and $C_{W}=3$ pieces at $Q_{W}$, while buffer $Q_{R}$ does not requires a limited capacity. Fully loaded Steel cassettes have a maximum capacity of 50 tons and are only transported when fully loaded. Initially, 10 empty cassettes are stored at $Q_{C}$.

While the production output of rectangular SSBs is conveniently located near the product warehouse, the transport of circular SSBs requires additional operations that include loading and unloading steel cassettes and transport between both buffers.

The finished production of both SSB types represent the simulation inputs that directly fill the buffers at $Q_{C}$ and $Q_{R}$ with hourly arrival intensity rates of $\lambda_{C}$ and $\lambda_{R}$.

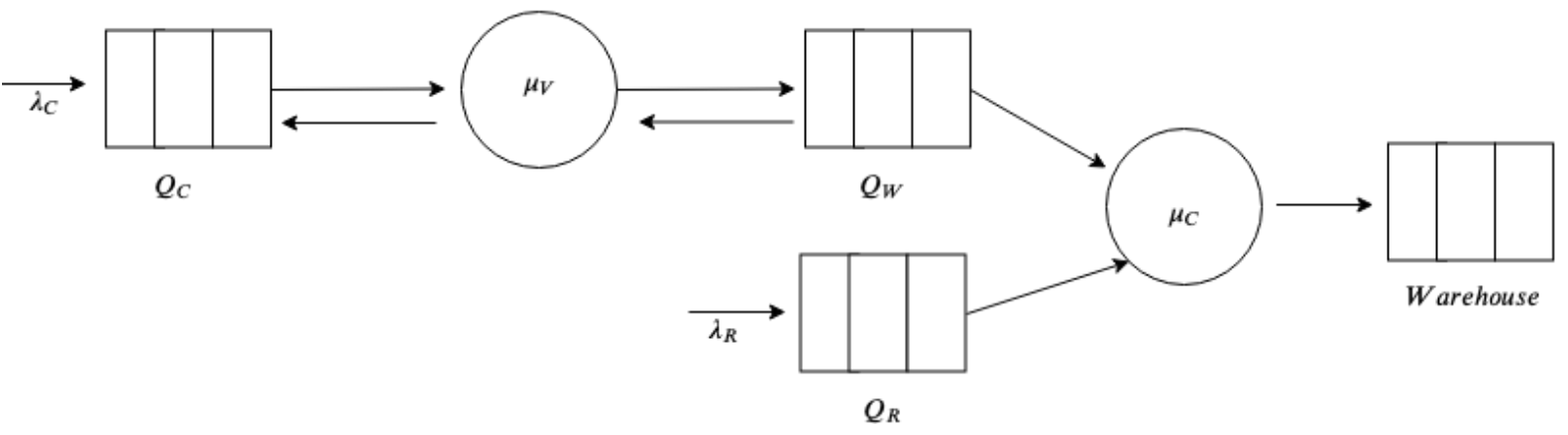

Figure 2: DES model.

The simulation model as depicted in Figure 2 is performed as follows:

- Once the SSB quantity at $Q_{C}$ exceeds the capacity of 50 tons a steel cassette is filled with circular SSBs and becomes available for transport with a heavy load vehicle to $Q_{W}$.

- The heavy load vehicle loads the full cassette and travels to $Q_{W}$.

- If the overhead crane is available, the steel cassette is unloaded directly and the vehicle returns to $Q_{C}$ otherwise the vehicle can either wait for the overhead crane to finish its current task or unload the cassette at $Q_{W}$ and return empty to retrieve a new full cassette, if available.

- The overhead crane alternates between unloading SSBs from steel cassettes from $Q_{W}$ or the vehicle, or from $Q_{C}$ by prioritizing rectangular SSBs as long as the number of steel cassettes and $Q_{W}$ does not exceed 1, in which case the priorities swap.

In the initial phase of the discrete-event simulation, the events generated, starting by filling buffers at $Q_{C}$ and $Q_{R}$ at time 0 with a normally distributed random quantity of $\lambda_{C i}$ and $\lambda_{R i}$ for each hour $i$ as given in Table I. Each event is assigned its source, which is in this case both buffers, time, and generated quantity. All events are inserted into list $E$, which is then sorted by time. The simulation is then performed by running through each event in the list and recalculating the values at queues and starting actions for heavy load vehicle and the overhead crane.

The first check is triggered by available material at each of the buffers. In case of the SSBs available at $Q_{C}$ it is loaded into a steel cassette with available capacity. The overhead crane operation time $T_{C}$ depends on the quantity of the available material and steel cassette capacity. The next event time is then calculated by:

$$
E_{\text {next }}=\text { time }+ \text { normal }\left(T_{C}, S_{C}\right)
$$

In Eq. (1) normal presents a Gaussian randomly generated the average value of $T_{C}$ and standard deviation $S_{C}$. The new event is assigned the steel cassette as the source and inserted into the event list into the correct slot to keep the list sorted by time, which happens after each 
generated new event. When this event is processed the next time, the quantity of SSB is reduced by 50 and one empty steel cassette is reassigned as full.

The next check is handling the cassette status. If any full or nearly full steel cassette is available at $Q_{C}$, the next event is calculated by:

$$
E_{\text {next }}=\text { time }+ \text { normal }\left(T_{l}, S_{l}\right)+\text { normal }\left(T_{t}, S_{t}\right)
$$

which corresponds with loading the cassette onto the heavy load vehicle with time $T_{l}$ and transporting to the buffer $Q_{w}$, which takes $T_{t}$. At this buffer different options are possible. If the overhead crane is not occupied by other tasks, the unloading of the steel cassette begins immediately, prompting the next event the returning of the heavy load vehicle to $Q_{C}$, unloading the cassette to the buffer and returning to retrieve the new one, or waiting for the overhead crane to become available, with the times for each option being calculated as follows:

$$
\begin{gathered}
E_{\text {next }}=\text { time }+\operatorname{normal}\left(T_{C}, S_{C}\right)+\operatorname{normal}\left(T_{t}, S_{t}\right) \\
E_{\mathrm{next}}=\operatorname{time}+\operatorname{normal}\left(T_{l}, S_{l}\right)+\operatorname{normal}\left(T_{t}, S_{t}\right) \\
E_{\mathrm{next}}=\operatorname{time}+t_{w}+\operatorname{normal}\left(T_{t}, S_{t}\right)
\end{gathered}
$$

where $t_{w}$ presents the maximal waiting time. In the case, the complete waiting time elapses, the heavy load vehicle returns to $Q_{C}$ as given in Eq. (5), otherwise Eq. (3) is calculated at the next event.

The events for the overhead crane are based on the position of the heavy load vehicle and status of its loaded steel cassette, full cassettes at $Q_{W}$ and SSB quantity at $Q_{R}$. Either of those trigger the event for unloading cassettes, that either unload cassettes at the vehicle or the $Q_{W}$, or subtracts the equivalent amount of SSBs at $Q_{R}$. In the first case, the status of the cassettes are set as empty, which allows the heavy load vehicle to either transport back to $Q_{C}$ or load an empty cassette and then transport it. These options are calculated again as in Eq. (3) or as follows:

$$
E_{\text {next }}=\text { time }+\operatorname{normal}\left(T_{C}, S_{C}\right)+\operatorname{normal}\left(T_{l}, S_{l}\right)+\operatorname{normal}\left(T_{t}, S_{t}\right)
$$

While the events describe here focus primarily on the heavy load vehicle, more precisely its position and status of its steel cassette (if loaded), each start of unloading also triggers the status of the overhead crane, which is either available or busy. The busy status of the overhead crane is set each time an event triggers emptying, while it is reset to available automatically after normal $\left(T_{C}, S_{C}\right)$ each time.

\section{RESULTS}

\subsection{Industry 4.0 maturity assessment}

The Industry 4.0 Maturity Index classified observed company in stage one (computerisation) [18]. The company is in a phase, which has to prepare the basis for digitalisation. Different information technologies are used in isolation from each other within the company.

Sales and production planning are using the same information system and are well supported. Warehouses and production lack of information system support. There is a great opportunity for automation and IT support to decide on product movements between the production and the warehouse.

The Digital Maturity Model 4.0 classified observed company between sceptics [19]. Sceptics are technology-sluggish firms that have limited experience innovating or applying an outside-in approach to strategic planning. Again, the most obvious gap is observed in production and warehouses. Communication between them is mostly oral, there is no visibility of products, work in progress, workers, transportation means in an information 
system. Work is based on searching for almost everything what is needed for completion of work. Employees work based on their experience and habits.

\subsection{DES results}

Two scenarios are compared in order to analyse the transport alternatives between the production of circular SSBs and the warehouse. In the current solution the SSBs are transported by using tractors to the product warehouse (marked in Table II), and the tractor operator is also used for the operation of the overhead crane. Meanwhile, in the second scenario, the heavy load vehicle works as an automated vehicle and is independent on the overhead crane operation. Both alternatives were tested on the average arrival intensity at the input buffers for circular and rectangular SSBs. The average SSB arrival intensity based on historic production data is presented in Table I, which represents the expected load of the system.

Table I: Hourly arrival rates of SSBs.

\begin{tabular}{|c|c|c|c|c|}
\hline \multirow{2}{*}{ Hour } & \multicolumn{2}{|c|}{ Circular $\left(\lambda_{C}\right)$} & \multicolumn{2}{c|}{ Rectangular $\left(\lambda_{R}\right)$} \\
\cline { 2 - 5 } & $\begin{array}{c}\text { Avg. } \\
\left(10^{3} \mathrm{~kg}\right)\end{array}$ & $\begin{array}{c}\text { Std. dev. } \\
\left(10^{3} \mathrm{~kg}\right)\end{array}$ & $\begin{array}{c}\text { Avg. } \\
\left(10^{3} \mathrm{~kg}\right)\end{array}$ & $\begin{array}{c}\text { Std. dev. } \\
\left(10^{3} \mathrm{~kg}\right)\end{array}$ \\
\hline 0 & 11.91 & 10.85 & 12.44 & 7.92 \\
\hline 1 & 14.69 & 12.27 & 9.69 & 8.40 \\
\hline 2 & 14.60 & 12.36 & 10.45 & 7.65 \\
\hline 3 & 14.75 & 10.87 & 10.07 & 7.57 \\
\hline 4 & 14.10 & 9.51 & 10.49 & 8.34 \\
\hline 5 & 13.78 & 10.61 & 10.45 & 9.93 \\
\hline 6 & 12.51 & 10.11 & 15.24 & 6.55 \\
\hline 7 & 11.94 & 7.85 & 18.45 & 8.49 \\
\hline 8 & 13.02 & 8.37 & 16.88 & 10.28 \\
\hline 9 & 13.23 & 10.68 & 17.07 & 9.95 \\
\hline 10 & 13.87 & 8.28 & 15.36 & 8.92 \\
\hline 11 & 13.52 & 9.51 & 14.91 & 7.64 \\
\hline 12 & 13.88 & 9.09 & 11.09 & 7.88 \\
\hline 13 & 14.00 & 12.10 & 10.32 & 10.44 \\
\hline 14 & 16.66 & 14.16 & 11.93 & 10.12 \\
\hline 15 & 9.80 & 12.21 & 9.29 & 9.07 \\
\hline 16 & 11.48 & 12.84 & 11.22 & 8.33 \\
\hline 17 & 13.14 & 11.41 & 9.21 & 8.21 \\
\hline 18 & 13.21 & 12.41 & 9.91 & 8.59 \\
\hline 19 & 13.72 & 10.54 & 10.69 & 7.34 \\
\hline 20 & 13.90 & 13.07 & 11.16 & 9.56 \\
\hline 21 & 13.46 & 14.73 & 11.25 & 10.19 \\
\hline 22 & 10.13 & 15.01 & 9.17 & 10.01 \\
\hline 23 & 10.53 & 3.63 & 11.54 & 3.00 \\
\hline
\end{tabular}

According to the specification for the heavy load vehicle and for the overhead crane, the following average times and standard deviations for operation are expected for comparison of using the heavy load vehicle versus the current solution by using tractors:

- Transport time: $T_{t}=6 \mathrm{~min}, S_{t}=0.5 \mathrm{~min}$ (for the heavy load vehicle); 
- Steel cassette loading/unloading time: $T_{l}=6 \mathrm{~min}, S_{l}=0.8 \mathrm{~min}$;

- Overhead crane operation time: $T_{C}=9 \mathrm{~min}, S_{C}=2 \mathrm{~min}$ per $10.000 \mathrm{~kg}$ of SSBs.

The DES was implemented in Visual studio $2017 \mathrm{C \#}$ and tested on the Windows 10 operating system with an Intel Core i7-8700 3.2 GHz processor. Both scenarios were run for 10.000 iterations, which provided stable average results first at the arrival intensity presented in Table I and again with a constantly available material at the input buffer in order $Q_{C}$ to test the maximal throughput performance of the system. The simulation results are given in Table II and displayed in Fig. 3.

Table II: Simulation results.

\begin{tabular}{|l|c|c|c|c|}
\hline \multicolumn{1}{|c|}{ Transport type } & Arrival intensity & $\begin{array}{c}\text { Daily throughput } \\
\left(10^{3} \mathrm{~kg}\right)\end{array}$ & Trips & $\begin{array}{c}\text { Crane utilization } \\
(\%)\end{array}$ \\
\hline Heavy load vehicle & $\lambda_{C}, \lambda_{R}$ & 692.23 & 14.06 & 32.50 \\
\hline Tractor (current state) & $\lambda_{C}, \lambda_{R}$ & 692.25 & 28.17 & 32.49 \\
\hline Heavy load vehicle & $\lambda_{C M a x}, \lambda_{R}$ & 1491.58 & 29.68 & 71.19 \\
\hline Tractor & $\lambda_{C M a x}, \lambda_{R}$ & 1376.74 & 62.72 & 68.40 \\
\hline Heavy load vehicle & $\lambda_{C M a x}, \lambda_{R M a x}$ & 2051.58 & 25.16 & 99.99 \\
\hline Tractor & $\lambda_{C M a x}, \lambda_{R M a x}$ & 2044.15 & 53.22 & 99.99 \\
\hline
\end{tabular}

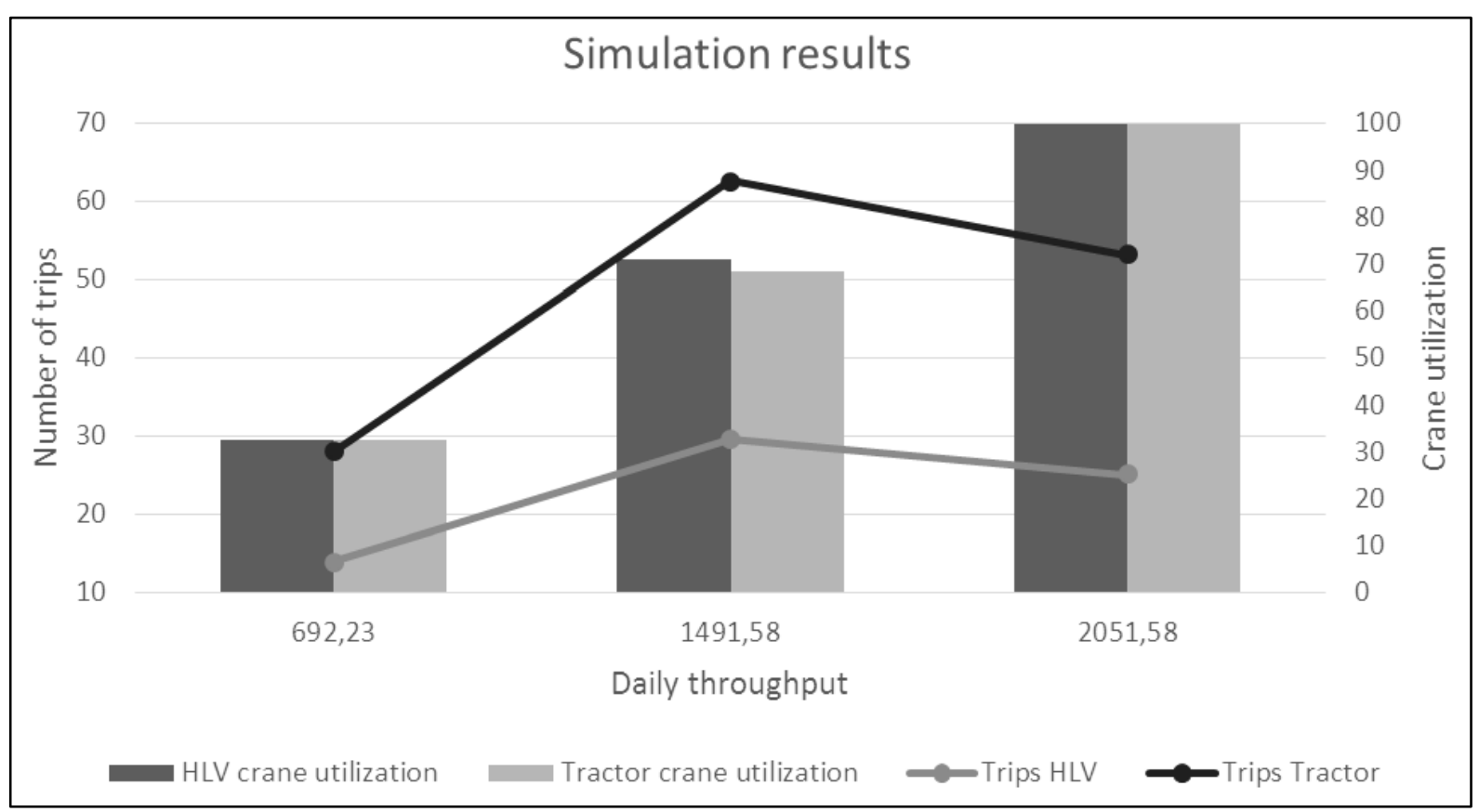

Figure 3: Graphical representation of simulation results.

At the normal production workload, the simulation revealed that the heavy load vehicle outperforms the application of tractors by reducing the number of trips, while both solutions manage to transport the complete amount of circular SSB profile to the product warehouse. At an increased load of circular SSBs the automatic heavy load vehicle provides a better option as there is no need for the driver to operate the overhead crane as well, which provides additional delays. At maximal workload of both circular as well as rectangular SSBs the overhead crane presents the bottleneck, which also has an impact on the buffer $Q_{W}$ due to its capacity for only 3 steel cassettes. Although the total throughput in this case is virtually the same for both scenarios, this is due to the high arrival rate at $Q_{R}$. 


\section{DISCUSSION}

The methodology of the transition on more mature Industry 4.0 level is presented in combination with a demonstration of the use of proper tools. In order to avoid resolving local problems, which solutions can most likely not contribute to improving the performance of the entire company, we have included maturity models. By using them, we localized undeveloped area in company's value chain that inhibits the progress of the whole system. In our case, we used two models, the Industry 4.0 Maturity Index and the Digital Maturity Model 4.0. The use of the second one was optional. Assessment with the Industry 4.0 Maturity Index revealed that researched company is not digitally mature, at the same time it is also lacking in the field of automation. In the second step, we measured digital maturity, which revealed the existence of information islands. From knowing the characteristics of assessed maturity state and analyse of mapping of business processes and their IT support, we discovered the biggest gap between production and warehouse. In the current state, material flow on this connection depends on the operator who assigns the work itself according to his vision of the current priorities. The operator does not know the details of the output of the products from the production, as well as the content of the planned shipments. For the transition to a higher level of maturity, it is necessary to automate product movements and to establish a decision-making system that will guide the automotive vehicle, in our case the heavy load vehicle, in such a sequence that the travelled route would be the shortest. The capacity of each movement should be maximally increased in direction to the maximum sustainable for the transport route. A group of experts examined all possible technical, technological, and organizational solutions and excluded the most appropriate in terms of available financial resources, the dangerous working environment of extreme temperatures and the implementation of the transport route. In this way, the input for testing with DES was provided. Based on results in Table II, a number of trips are double in case of the tractor compared to the heavy load vehicle, meanwhile, the throughput capacity and the overhead crane utilization stays almost the same for both transportation devices. According to the results of simulation analysis, the automatic heavy load vehicle outperforms the current transportation system in all three cases of the arrival rate. As well, the automatic heavy load vehicle does not need an operator for guiding the vehicle, which is good from the utilization point of view.

\section{CONCLUSIONS}

In this paper, the level of the maturity index for the producer of steel bars by using models known as Industry 4.0 Maturity Index and the Digital Maturity Model 4.0 have been analysed. Assessment with the Industry 4.0 Maturity model revealed the relatively low level of the maturity index and the opportunity to invest resources in the company's intralogistics process. For this reason, an automatic heavy load vehicle with a special steel cassette for carrying 50 tons of materials (SSBs) in one route has been used in our research study. In order to test the utilization and the system performance of a heavy load vehicle, the discrete event simulation has been applied. The logistics (i.e. availability of the overhead crane for loading and unloading the vehicle, transport between the production site and the product warehouse) along with technological process (throughput performance of the production plant) has been analysed. Location of workstations and workplaces as well as loading/unloading places for the transporter has been defined by the layout. According to the results of simulation analysis, the automatic heavy load vehicle outperforms the current transportation system in all three cases of the arrival rate. The general outcome of the proposed research study is connectedness between the discrete event simulation and the maturity model. The simulation as an efficient 
tool is used to support managers in understanding the level of automation (maturity index) that can be applied for increasing the efficiency in their production systems.

For the future work, we are planning to analyse the throughput performance of a heavy load vehicle on a larger scale (transport between two production facilities). It would also be interesting to investigate the energy efficiency of a heavy load vehicle and to use the method of multi-objective optimization with an emphasis on throughput, cost and sustainability.

\section{ACKNOWLEDGEMENT}

This work was supported by Slovenian Research Agency (ARRS): Methodology for Building an Integral Model of Transport-Warehouse Processes to Enhance Intralogistics System Efficiency, grant number: L5-8237.

\section{REFERENCES}

[1] Vrecko, I.; Kovac, J.; Rupnik, B.; Gajsek, B. (2019). Using queuing simulation model in production process innovations, International Journal of Simulation Modelling, Vol. 18, No. 1, 47-58, doi:10.2507/IJSIMM18(1)458

[2] Bahrin, M. A. K.; Othman, M. F.; Azli, N. H. N.; Talib, M. F. (2016). Industry 4.0: A review on industrial automation and robotic, Journal Teknologi, Vol. 78, No. 6-13, 137-143, doi: $\underline{10.11113 / \text { jt.v78.9285 }}$

[3] Vieira, A. A. C.; Dias, L. M. S.; Santos, M. Y.; Pereira, G. A. B.; Oliveira, J. A. (2018). Setting an Industry 4.0 research and development agenda for simulation - a literature review, International Journal of Simulation Modelling, Vol. 17, No. 3, 377-390, doi:10.2507/ IJSIMM17(3)429

[4] Tasić, N.; Đurić, Ž.; Malešević, D.; Maksimović, R.; Radaković, N. (2018). Automation of process performance management in a company, Technical Gazette, Vol. 25, No. 2, 565-572, doi:10.17559/TV-20151010074417

[5] Kagermann, H.; Wahlster, W.; Helbig, J. (2013). Recommendations for implementing the strategic initiative Industrie 4.0: Securing the future of German manufacturing industry, final report of the Industrie 4.0 working group, from: https://www.din.de/blob/76902/ e8cac883f42bf28536e7e8165993flfd/recommendations-for-implementing-industry-4-0-data.pdf, accessed on 15-04-2019

[6] Turner, C. J.; Hutabarat, W.; Oyekan, J.; Tiwari, A. (2016). Discrete event simulation and virtual reality use in industry: new opportunities and future trends, IEE Transactions on HumanMachine Systems, Vol. 46, No. 6, 882-894, doi:10.1109/THMS.2016.2596099

[7] Sommer, L. (2015). Industrial revolution - Industry 4.0: Are German manufacturing SMEs the first victims of this revolution?, Journal of Industrial Engineering and Management, Vol. 8, No. 5, 1512-1532, doi: $10.3926 /$ jiem. 1470

[8] Veza, I.; Mladineo, M.; Gjeldum, N. (2016). Selection of the basic lean tools for development of Croatian model of innovative smart enterprise, Technical Gazette, Vol. 23, No. 5, 1317-1324, doi:10.17559/TV-20160202120909

[9] Sternad, M.; Lerher, T.; Gajšek, B. (2018). Maturity levels for logistics 4.0 based on NRW's Industry 4.0 maturity model, Proceedings of the $18^{\text {th }}$ International Scientific Conference Business Logistics in Modern Management, 695-708

[10] Klitou, D.; Conrads, J.; Rasmussen, M. (2017). Germany: Industrie 4.0. Digital Transformation Monitor, from https://ec.europa.eu/growth/tools-databases/dem/monitor/sites/default/files/ DTM_Industrie\%204.0.pdf, accessed on 15-04-2019

[11] Kolberg, D.; Zühlke, D. (2015). Lean automation enabled by Industry 4.0 technologies, IFACPapersOnLine, Vol. 48, No. 3, 1870-1875, doi:10.1016/j.ifacol.2015.06.359

[12] Acatech-Plattform Industrie 4.0. Industrie 4.0 - Whitepaper FuE Themen, from https://www.din.de/blob/67744/de1c706b159a6f1baceb95a6677ba497/whitepaper-fue-themendata.pdf, accessed on 30-06-2019 
[13] Lasi, H.; Fettke, P.; Kemper, H.-G.; Feld, T.; Hoffmann, M. (2014). Industry 4.0, Business \& Information Engineering, Vol. 6, No. 4, 239-242, doi:10.1007/s12599-014-0334-4

[14] Prester, J.; Buchmeister, B.; Palčič, I. (2018). Effects of advanced manufacturing technologies on manufacturing company performance, Strojniski vestnik - Journal of Mechanical Engineering, Vol. 64, No. 12, 763-771, doi:10.5545/sv-jme.2018.5476

[15] Pöppelbuß, J.; Röglinger, M. (2011). What makes a useful maturity model? A framework of general design principles for maturity models and its demonstration in business process management, Proceedings of the $19^{\text {th }}$ European Conference on Information Systems, 13 pages

[16] Becker, J.; Knackstedt, R.; Pöppelbuß, J. (2009). Developing maturity models for IT management - a procedure model and its application, Business \& Information Systems Engineering, Vol. 1, No. 3, 213-222 doi:10.1007/s12599-009-0044-5

[17] Rodič, B. (2017). Industry 4.0 and the new simulation modelling paradigm, Organizacija Journal of Management, Informatics and Human Resources, Vol. 50, No. 3, 193-207, doi:10.1515/orga-2017-0017

[18] Ojstersek, R.; Buchmeister, B. (2017). Use of simulation software environments for the purpose of production optimization, Proceedings of the $28^{\text {th }}$ DAAAM International Symposium, 750-758, doi:10.2507/28th.daaam.proceedings.106

[19] Gingu, E. I.; Zapciu, M.; Cavalieri, S. (2017). Production systems flow modelling using decomposition method and required buffers, International Journal of Simulation Modelling, Vol. 16, No. 2, 207-218, doi:10.2507/IJSIMM16(2)2.367

[20] Duplakova, D.; Teliskova, M.; Duplak, J.; Torok, J.; Hatala, M.; Steranka, J.; Radchenko, S. (2018). Determination of optimal production process using scheduling and simulation software, International Journal of Simulation Modelling, Vol. 17, No. 4, 609-622, doi:10.2507/ IJSIMM17(4)447

[21] Grguraš, D.; Kramar, D. (2017). Optimization of hybrid manufacturing for surface quality, material consumption and productivity improvement, Strojniski vestnik - Journal of Mechanical Engineering, Vol. 63, No. 10, 567-576, doi:10.5545/sv-jme.2017.4396

[22] Kampa, A.; Golda, G.; Paprocka, I. (2017). Discrete event simulation method as a tool for improvement of manufacturing systems, Computers, Vol. 6, No. 1, doi:10.3390/ computers6010010

[23] Ištoković, D.; Perinić, M.; Doboviček, S.; Bazina, T. (2019). Simulation framework for determining the order and size of the product batches in the flow shop: A case study, Advances in Production Engineering \& Management, Vol. 14, No. 2, 166-176, doi:10.14743/apem2019.2.319

[24] Torres, L.; Pina, V.; Martí, C. (2015). Factors explaining the impact of performance measures in European local governments, Lex Localis - Journal of Local Self-Government, Vol. 13, No. 2, 229-248, doi:10.4335/13.2.229-248(2015)

[25] Schuh, G.; Anderl, R.; Gausemeier, J.; ten Hompel, M.; Wahlster, W. (2017). Industrie 4.0 Maturity Index. Managing the Digital Transformation of Companies (acatech STUDY), from http://www.acatech.de/de/publikationen/publikationssuche/detail/artikel/industrie-40-maturityindex-die-digitale-transformation-von-unternehmen-gestalten.html, accessed on 30-06-2019

[26] Gill, M.; van Boskirk, S. (2016). The Digital Maturity Model 4.0 - Benchmarks: Digital Business Transformation Playbook, from https://forrester.nitro-digital.com/pdf/Forresters\%20Digital\%20Maturity\%20Model\%204.0.pdf, accessed on 30-06-2019

[27] Gajšek, B. (2019). Maturity model as a tool for transition in logistics 4.0 on operational level, Proceedings of the $9^{\text {th }}$ International Scientific-practical Conference Logistics Systems in Global Economy, 17-21 